\title{
Pneumococcal immunization program in Montérégie, Québec: Feasibility study
}

\author{
Maryse Guay MD MSc FRCPC ${ }^{1,2}$, Philippe De Wals MD PhD ${ }^{1,2}$, Réjean Hébert MD MPhil ${ }^{3}$
}

\begin{abstract}
A lthough the pneumococcal vaccine has been available in Canada since 1978, when studying the problem in 1995, we observed its very low use. However, pneumococcal infection constitutes an important cause of morbidity and mortality. Even with appropriate antibiotic treatment, approximately $25 \%$ of people with pneumococcal pneumonia will die; this proportion increases to $40 \%$ among those 65 years of age and older $(1,2)$. With the growing phenomena of antibiotic resistant Streptococcus pneumoniae (3-7), vaccination against pneumoccal disease becomes even more desirable. Pneumococcal vaccination is recommended by many official bodies $(1,2,8-10)$; for these reasons, we decided to conduct a study to evaluate a pneumococcal vaccination program.
\end{abstract}

\section{MONTÉRÉGIE HEALTH REGION}

After the Montreal region, Montérégie is the second largest of the 18 health regions in the province of Quebec. The total population is 1.3 million persons living in urban sectors, mainly around the Montreal belt, and rural and semirural sectors. Public health services are provided by 19 local centres for community services (CLSC) and 10 hospitals. Vaccination is offered by physicians in private practice and by the 19 CLSCs. For influenza vaccination, physicians give $70 \%$ of the 80,000 doses of vaccine, the CLSCs give $20 \%$, and hospitals and chronic care facilities give the remaining $10 \%$.

\section{LITERATURE REVIEW}

Before proposing a program, the literature was reviewed to discover the best strategies that could be applied. It was found that most trials were done in hospital or clinical settings (1122 ), and only a few were done in the community (23-25). In hospitals, a standing order seemed to be the most effective way to achieve high vaccine coverage (12). In long term care settings, the nomination of a person responsible for the pneumococcal vaccination has been highly effective (22). In the community, programs that have used resources already involved in vaccination, such as influenza vaccination $(23,25)$, have been more successful than those that have implemented new vaccination clinics dedicated specifically to pneumococcal vaccination (24). After the review, a pneumococcal vaccination program based on the influenza program was proposed.

\section{THE TARGET POPULATION}

The population targeted was identified by the provincial immunization protocol (10). It included adults 65 years of age or older, including those in good health; adults with chronic lung disease, chronic heart disease, cirrhosis, diabetes or alcoholism; adults and children two years of age and over suffering from nephrotic syndrome, asplenia, human immunodeficiency virus infection, conditions associated with immunosuppression, sickle-cell anemia or chronic leakage of cerebrospinal fluid.

The Public Health Department coordinated and promoted the program, and provided the vaccine to the vaccinators. Pharmacists sold the vaccine and gave information about the vaccine to their clientele. Regarding the actual vaccination, three main areas were targeted: the acute-care hospital, where

\footnotetext{
${ }^{\prime}$ Direction de la santé pubique, Régie régional de la santé et des services sociaux de la Montérégie, Saint-Hubert, Quebec; ${ }^{2}$ Département des sciences de la santé communautaire, Univerisité de Sherbrooke; ${ }^{3}$ Centre de recherche en gérontologie et gériatrie, Institut universitaire de gériatrie de Sherbrooke, Sherbrooke, Québec

Correspondence and reprints: Dr Maryse Guay, Sante Publique Monteregie, 3000 - 5245 bout cousineau, Saint-Hubert, Quebec J3Y 6J8. Telephone 514-679-6772,fax 514-928-6781, e-mail m.guay@rrssi6.gouv.qc.ca
} 


\section{TABLE 1}

Characteristics of the two Local Centres for Community Services (CLCS) participating in the pneumococcal study

\begin{tabular}{lrr}
\hline & Free* $^{*}$ & Pay $^{+}$ \\
\hline Number of people 65 years old and older & 9665 & 9882 \\
Number of influenza vaccinators & 31 & 34 \\
Estimate of number of people 65 years old & 3866 & 3953 \\
$\quad$ and older receiving influenza vaccine in & & \\
$\quad$ 1996/97 & & \\
Percentage of vaccine given by CLSC clinic & $18 \%$ & $22 \%$ \\
Pneumococcal vaccine sold in 1996/1997 & 31 & 19 \\
\hline
\end{tabular}

*Vaccine administered for free in CLSC des Maskoutains, Saint-Hyacinthe, Québec; 'Vaccine administered for a fee in CLSC Vallée-des-Forts, StJean-sur-Richelieu, Québec

patients could be vaccinated on discharge when they were still 'captive' and relatively healthy; long term care hospitals, where patients could be vaccinated on admission while they were still fairly healthy; and the community at large, where CLSCs and physicians could vaccinate the target population all year round. In this last instance, it may be most effective to vaccinate in the autumn with the influenza vaccination program.

To evaluate the likely effectiveness of the proposed pneumococcal vaccination program, a study with the following objectives was conducted: to achieve a vaccine uptake rate of $40 \%$ in the 65 years and older age group; to evaluate the impact of providing the vaccine free of charge; to evaluate the different components of the program; and to evaluate the feasibility of using the VAXIN software (Centre de santé publique de Québec) for vaccination recording.

\section{METHODOLOGY}

Study design: A quasiexperimental design, a pretest and post-test nonequivalent control group design with two experimental groups was used. One CLSC territory provided the vaccine free of charge, and one CLSC provided vaccine for a fee. Originally it was assumed that the free or pay vaccine group would be randomly chosen. To avoid problems of contamination, the rest of the population of Quebec was originally to be used as the control group.

The two experimental CLSCs were chosen to be as similar as possible using the Matusita distance calculation method (26). With this method by a mathematical approach, the Matusita distance on nine sociodemographical variables for all the possible pairs of CLSCS in Montérégie (171 pairs possible) was determined. The pair with the smallest average distance is the best matched pair. Of the pair, the CLSC offering free vaccine was going to be chosen randomly. But one of the selected CLSCs threatened to withdraw from the study if it was not chosen as the pay vaccine site, so the pay vaccine group was a volunteer group. Data from the rest of Quebec could not be used because this information became confidential by the time the study began (personal communication). Therefore, two other CLSCs in Montérégie were chosen as the two control groups. Study population: Although the eventual target population of the program was large (including those with chronic illness), for the purposes of the study, efforts were concentrated on
TABLE 2

Ratio of pneumococcal vaccines administered to influenza vaccines distributed

\begin{tabular}{lcc}
\hline Site of vaccination & Free vaccine* & Pay vaccine $^{\dagger}$ \\
\hline $\begin{array}{l}\text { Local Centres for Community } \\
\text { Services clinic }\end{array}$ & $\begin{array}{c}\text { Approximately } \\
100 \%\end{array}$ & $35 \%$ \\
Long term care residence & $70 \%$ to $80 \%$ & $30 \%$ \\
Physicians & $10 \%$ to $100 \%$ & $81 \%$ \\
\hline
\end{tabular}

*Vaccine administered for free in CLSC des Maskoutains, Saint-Hyacinthe, Québec; ${ }^{+}$Vaccine administered for a fee in CLSC Vallée-des-Forts, StJean-sur-Richelieu, Québec

documenting the results in people 65 years of age and older, because it is the only part of the target population for which an accurate denominator was available.

Data collection: To determine the vaccine coverage for the numerator, a vaccination slip for each dose of pneumococcal vaccine administered was filled in by the vaccinator. As a further check, pharmacists in all four of the CLSC areas was asked to provide information on doses of pneumococcal vaccine sold. This information was collected in spring 1997 for the pretest measurement. It will be collected again for the years 1998 and 1999, corresponding to the total period of the study. Canadian census data were used for the denominator.

\section{RESULTS}

The two experimental CLSCs chosen were CLSC des Maskoutains in the Saint-Hyacinthe area for the free vaccine, and CLSC Vallée-des-Forts in the Saint-Jean-sur-Richelieu area for the pay vaccine. In Table 1, the pretest data show that almost 10,000 people aged 65 years and over live in the area served by the two experimental CLSCs. Almost 4000 people in the targeted age group received influenza vaccine from October 1996 to February 1997 , and approximately $20 \%$ of the people received the vaccine in the CLSCS clinics. Finally, the total number of doses of pneumococcal vaccine sold in the year preceding this study was negligible.

The project began in the fall of 1997 , with promotion beginning in September. Vaccine delivery began on October 10 , 1997. In less than two weeks, the first 2500 doses had been given, and there were many requests for more vaccines (doses of Pnu-Imune 23, Wyeth Ayerst Canada). On November 4, 1997, another 1000 doses were obtained, which were rapidly used (Pneumovax 23, Merck Frosst Canada Inc, Vaccine Division). Another 300 doses of Pnu-Imune were received at the end of November. The authors were still getting requests that they were unable to fill. It is impossible to estimate the number of people 65 years of age and over or the number of people with chronic illness who received the vaccine. The postal strike before Christmas 1997 delayed the return of the vaccination slips filled by the vaccinators. Also, the ice storm of the first week of January 1998 made it impossible to obtain precise information on the number of vaccines and the recipients risk factor category. Only rough ratios of the number of 
pneumococcal vaccines administered to the doses of influenza vaccines the Public Health Department distributed, and comparisons between the free and pay vaccine areas can be made (Table 2).

In the free vaccine CLSC clinic, almost all the people receiving influenza vaccine received pneumococcal vaccine, while in the pay vaccine CLSC, approximately $32 \%$ of the influenza vaccinees agreed to pay for the pneumococcal vaccine. In long term care residences and hospitals, data from only five of the 12 vaccinators in the free vaccine area were obtained. The ratio of residents receiving influenza vaccine who also received pneumococcal vaccine varied from $70 \%$ to $80 \%$. In the pay vaccine area, only one long term care hospital returned the data; $30 \%$ of their residents receiving influenza vaccine were willing to pay for pneumococcal vaccine. For the physicians, slightly more than half in the free vaccine territory (10 of 17) returned partial or complete information on pneumococcal vaccination. This represents $10 \%$ to $100 \%$ of the influenza vaccinees in physicians' practices receiving both vaccines. In the pay territory, only one physician returned vaccination slips on pneumococcal vaccination, reporting that $81 \%$ of the people who received influenza vaccine also received pneumococcal vaccine. In the coming weeks, more precise data will be available and the effects of the program will be evaluated more rigorously.

\section{DISCUSSION}

The experimental setting may limit the generalizability of our program, but we tried to interfere as little as possible to simulate real world implementation conditions. With minimal interference, we had less control over the program process. For example, in long term care residences or hospitals, we recommended that the vaccine be given to people with a relatively good life expectancy. It was almost impossible to ensure that this recommendation was followed.

Even if we do not have all the results yet, we have good reason to believe that the majority of private physicians in the pay CLSC territory did nothing about pneumococcal vaccina- tion. Some of them may have been aware of the study hypothesis and decided not to offer the vaccine to force the issue of a free vaccination program.

We can confirm that with minimal promotion strategy, we can attain good coverage with a free vaccine program. We also learned that when the vaccine is offered with the influenza vaccine, as happened in the CLSC clinics and in one of the long term care hospitals, the vaccine is accepted by $30 \%$ of the influenza vaccinees (incidentally, this long term care hospital is affiliated to the CLSC). What we do not know are the characteristics of the people who paid $\$ 20$ for pneumococcal vaccine. Are these people from higher socioeconomic levels? Does the program contribute to inequity if it is not backed by free vaccine? Further analysis is needed to answer these important questions.

Finally, we should remember that even if all of the people who are receiving influenza vaccine accept pneumococcal vaccine, this currently represents only $40 \%$ of the target population, and efforts need to be made to reach more of the population. The same logic can be applied to the pay vaccine, $30 \%$ of influenza vaccinees represents only $12 \%$ of the target population.

\section{CONCLUSIONS}

It is feasible to tag pneumococcal vaccination onto the influenza program, and it is more efficient to join the two programs that target almost the same population. The vaccine coverage achieved is a good start, but we realize that we are far from ideal vaccine coverage. Further results of the study, in particular those related to the use of a software package for registration, have been delayed and will be presented later.

ACKNOWLEDGEMENTS: This study was supported by the ministère de la Santé et des Services sociaux du Québec, Wyeth Ayerst Inc and Merck Frosst, Vaccine Division. Their support is appreciated. We also thank the nurses and personnel of the two CLSCS who made this study possible.

\section{REFERENCES}

1. Advisory Committee on Immunization Practices. Pneumococcal Polysaccharide Vaccine. Morb Mortal Wkly Rep 1989;38:64-76.

2. Comité consultatif national de l'immunisation. Guide canadien d'immunisation, 4e édition. Ottawa: Santé Canada, 1993:180.

3. Appelbaum PC. Antimicrobial resistance in Streptococcus pneumoniae: An overview. Clin Infect Dis 1992;15:77-83.

4. Centers for Disease Control and Prevention. Prevalence of penicillin-resistant Streptococcus pneumoniae - Connecticut, 1992-1993. Morb Mortal Wkly Rep 1994;43:216-23.

5. Friedland IR, Mccracken GH. Management of infections caused by antibiotic-resistant Streptococcus pneumoniae. N Engl J Med 1994;331:377-82.

6. Jetté L, Ringuette L. Souches de Streptococcus pneumoniae ayant une sensibilité réduite a la pénicilline $\mathrm{G}-$ Québec. Relevé des maladies transmissibles au Canada 1994;20:69-70.

7. Simor AE, Rachlis A, Louie L, Goodfellow J, Louie M. Emergence of penicillin-resistant Streptococcus pneumoniae in southern Ontario, 1993-1994. Can J Infect Dis 1995;6:157-60.

8. Fedson D, Henrichsen J, Makela PH, Austrian R. WHO recommendations on pneumococcal vaccination: Immunization of elderly people with polyvalent pneumococcal vaccine. Infection 1989;17:437-41.

9. United States Preventive Services Task Force. Guide to Clinical

Preventive Services: An Assessment of the Effectiveness of 169 Interventions. Baltimore: Williams \& Wilkins, 1989:363-8.

10. Comité sur l'immunisation du Québec. Protocole d'immunisation. Québec: Ministère de la Santé et des Services sociaux du Québec, 1995a, pagination multiple.

11. Klein RS, Adachi N. Pneumococcal vaccine in the hospital. Improved use and implications for high-risk patients. Arch Intern Med 1983;143:1878-81.

12. Klein RS, Adachi N. An effective hospital-based pneumococcal immunization program. Arch Intern Med 1986;146:327-9.

13. Bloom HG, Bloom JS, Krasnoff L, Frank AD. Increased utilization of influenza and pneumococcal vaccines in an elderly hospitalized population. J Am Geriatr Soc 1988;36:897-901.

14. Ratner ER, Fedson DS. Influenza and pneumococcal immunization in medical clinics, 1978-1980. Arch Intern Med 1983;143:2066-9.

15. Rodney WM, Chopivsky P, Quan M. Adult immunization: The medical record design as a facilitator for physician compliance. J Med Educ 1983:58:576-80.

16. McDonald CJ, Hui SL, Smith DM, et al. Reminders to physicians from an introspective computer medical record: A two-year randomized trial. Arch Intern Med 1984;100:130-8.

17. Siebers MJ, Hunt VB. Increasing the pneumococcal vaccination 
rate of elderly patients in a general internal medicine clinic. J Am Geriatr Soc 1985;33:175-8.

18. Schreiner DT, Petrusa ER, Rettie CS, Kluge RM. Improving compliance with preventive medicine procedures in a house staff training program. South Med J 1988;81:1553-7.

19. Becker DM, Gomez EB, Kaiser DL, Yoshihahi A, Hodge RH. Improving preventive care at a medical clinic: How can the patient help? Am J Prev Med 1989;5:353-9.

20. Turner RC, Waivers LE, O'Brien K. The effect of patientcarried reminder cards on the performance of health maintenance measures. Arch Intern Med 1990;150:645-7.

21. Rodriguez RM, Baraff LJ. Emergency department immunization of the elderly with pneumococcal and influenza vaccines. Ann Emerg Med 1993;22:1729-32.
22. Morton MR, Spruill W], Cooper JW. Pharmacist impact on pneumococcal vaccination rates in long-term care facilities. Am J Hosp Pharm 1988;45:73.

23. Lyman DO. Pneumococcal immunization program - California, 1986-1988. Morb Mortal Wkly Rep 1989;38:517-9.

24. Campbell JF, Donohue MA, Nevin-Woods C, et al. The Hawaii Pneumococcal Disease Initiative. Am J Public Health 1993;83:1175-6.

25. Davidson M, Chamblee C, Campbell HG, et al. Pneumococcal vaccination in a remote population of high-risk Alaska Natives. Public Health Reports 1993;108:439-46.

26. Junod B, Wietlisbach V. Méthodes et stratégies d'évaluation du programme national suisse de recherche sur la prévention des maladies cardio-vasculaires. Rev Épidém Santé Publ $1981 ; 29: 315-25$. 


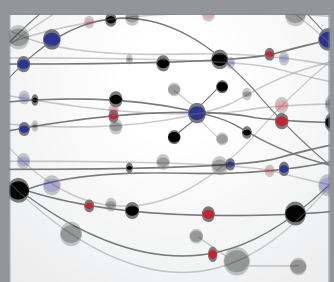

The Scientific World Journal
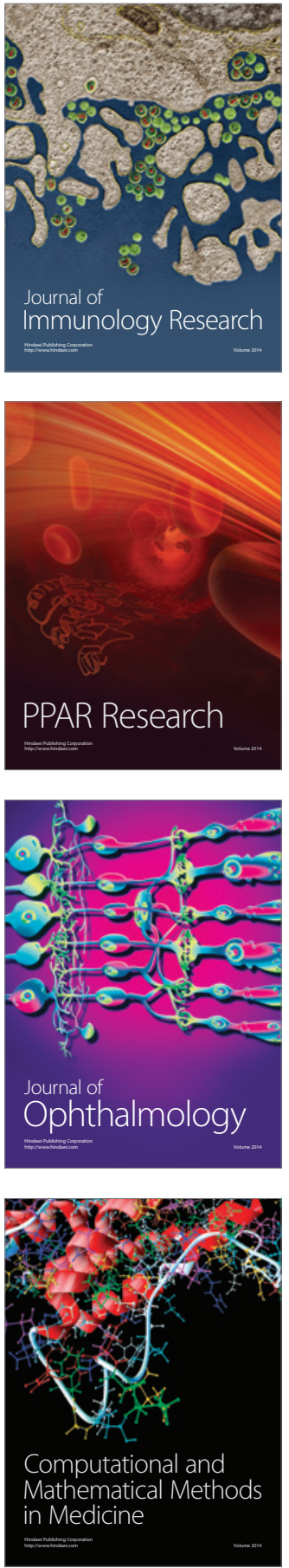

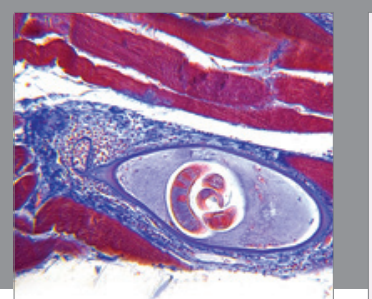

Gastroenterology Research and Practice

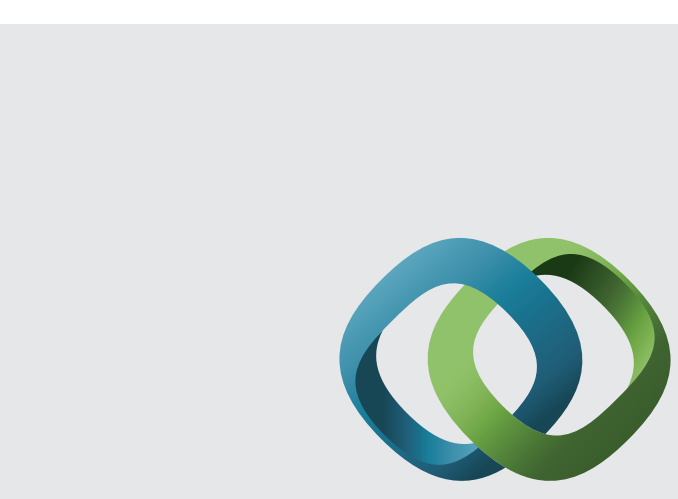

\section{Hindawi}

Submit your manuscripts at

http://www.hindawi.com
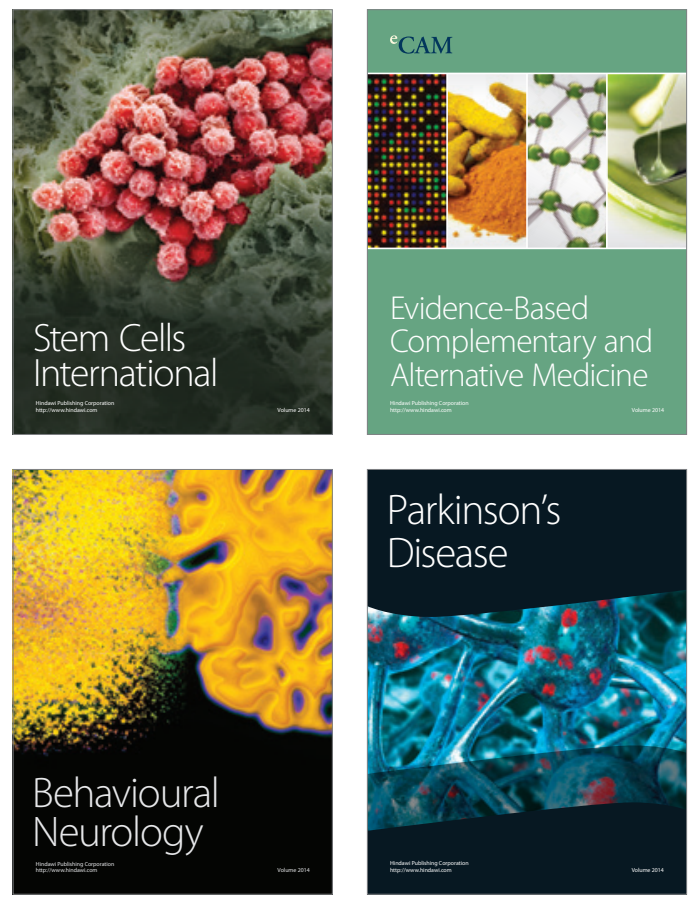
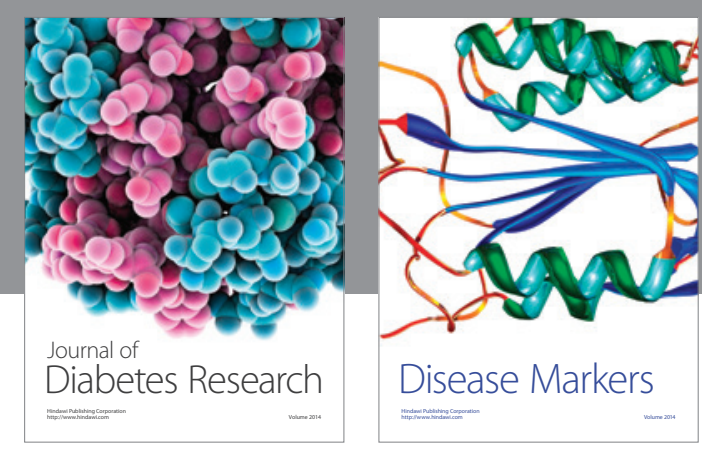

Disease Markers
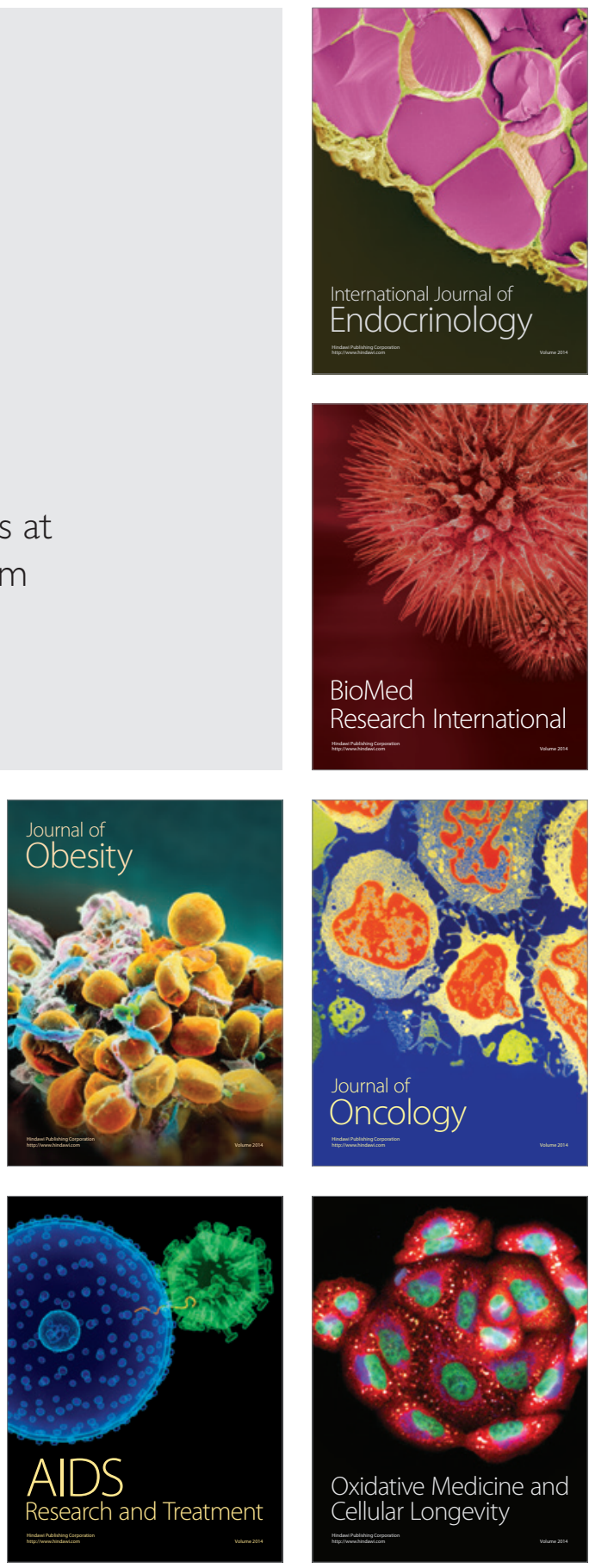